\title{
Compliance Theory: A Goal Framing Approach Julien Etienne
}

\author{
Postdoctoral Fellow \\ Centre for Analysis of Risk and Regulation \\ London School of Economics and Political Science \\ Houghton Street \\ London WC2A $2 \mathrm{AE}$ \\ United Kingdom \\ J.Etienne@1se.ac.uk
}

Presented at the Third Biennial Conference of the ECPR Standing Group on Regulatory

Governance, University College Dublin, 17-19 June 2010.

\section{Abstract}

This paper is a contribution to the theorization of regulatory compliance. It presents a framework for analyzing regulatees' responses to public regulation. It identifies the main variables and mechanisms through which regulatory policy may influence regulatees' preferences. Thus, it provides a theory for interpreting compliance and noncompliance behaviors. The article builds on Siegwart Lindenberg's Goal Framing Theory. The theoretical framework gives a consistent account of the cumulated and interactive influence of heterogeneous motives on (non)compliance decisions. It thus provides a better understanding of responses to regulation than there was before. The theoretical argument is supported by an extensive range of examples borrowed from the empirical literature on regulatory compliance. [109 words] 
In the first semester of 2010 , Greece was at the centre of public attention. Its huge public debt had made it the plaything of financial markets, and appeared to threaten the equilibrium of the whole Euro-zone. Questions were quickly raised as to why Greece had become so indebted. Journalists and academics uncovered several causes, but they found a particularly striking one in the pervasiveness of tax evasion, one of the various ways in which ingrained dispositions for noncompliance manifest themselves in Greek society. According to conservative estimates, unpaid taxes have amounted to an average of 20 billion Euros per year. Paradoxically, in the previous decade Greece had become increasingly wealthy, while state revenue has decreased. ${ }^{1}$ Widespread tax evasion had contributed to bringing Greece on its knees.

As this example shows, regulatory compliance can be a critical dimension of political steering. It is thus not surprising that it has received much attention by scholars. It is more surprising, however, that the numerous empirical studies on the subject have led to only limited theoretical progress (Hutter 2001). I argue that one of the reasons for this relatively disappointing outcome is the failure of compliance theorists to successfully address two important aspects of compliance and noncompliance decisions.

Firstly, they have struggled to build theories that would be at the same time internally consistent and able to account for the simultaneous influence on compliance decisions of heterogeneous motives such as material, emotional and normative goals. Secondly, they have also failed to take up the often counterintuitive effects of interactions between these different motives, such as those taking place between normative and material goals (as

\footnotetext{
${ }^{1}$ Tax revenue in Greece fell by $2.5 \%$ of GDP between 2000 and 2007, as economic growth averaged $4.1 \%$ a year (Sills and Weeks 2010).
} 
shown in Frey 1997), or between material and emotional goals (as shown in Makkai and Braithwaite 1994b).

In this paper I attempt to contribute to compliance theories and offer a better alternative to the currently available theoretical approaches. I propose a solution to the two interrelated issues underlined before: the variety and heterogeneity of goals in responses to regulation, and the effects of their interactions. My intention is also to provide a framework that can include numerous published findings and thus can be a synthesis of a great deal of published compliance research.

The paper builds on Lindenberg's goal framing theory (GFT) (Lindenberg 1993, 2000a; Lindenberg and Steg 2007). GFT is a theory of goal-oriented action taking stock of social psychologists' findings, especially goal systems theory (Kruglanski et al. 2002). According to GFT, actors anticipate and evaluate the consequences of the options available to achieve a goal, and choose the one that is likely to best satisfy their purpose. GFT also assumes that one's goals and the way one defines the situation are interrelated: perception and motivation tend to harmonize in a to-and-fro process. Therefore, goals tend to be situation dependent rather than stable across situations, and preferences are constructed rather than revealed. Besides, GFT accepts the idea that actors customarily assess options with reference to several, heterogeneous goals.

I am reformulating this path-breaking theory, providing various additions and modifications for the purpose of contributing to compliance theory. In this article, compliance is understood as behavior fitting expectations communicated to regulatees 
regarding how the former should or should not behave in a given domain. ${ }^{2}$ The role played in compliance behavior by incapacity, ignorance, or misunderstanding, is only incidentally considered, although that certainly is not anecdotal. To include all these aspects, one would have to go much further up the chain of causality than I am prepared to in these pages. Rather the argument in this article rests on the idea that goal framing theory offers a "useful fiction" (MacDonald 2003) of actual action processes.

In the next section, I propose an overview of the current state of compliance theory. The rest of the paper is organized in three main sections, corresponding to the three complementary parts of the framework: firstly, a taxonomy of goals that specifies the principal categories of motives for responding to regulation; secondly, a model of preference formation with several goals; thirdly, two mechanisms through which regulatory policy may impact on goals and options, and hence influence individual choices. The theoretical argument is supported by a number of examples and references from the compliance literature. Conclusions follow.

\section{A review of compliance theories}

Compliance and noncompliance are complex behaviors linked to a wide variety of causes that cannot be easily brought together in a parsimonious whole (Coombs 1980;

\footnotetext{
${ }^{2}$ This definition is close to Coombs' (1980). It is more inclusive than "conformity with the law" (Hutter 1997: 16-17) because regulatees may be asked to conform to expectations communicated in non-legal form (Hopkins 1994; e.g. Thaler and Sunstein 2009). It is also less normative than "conformity with policy objectives" since expectations communicated to regulatees may not be appropriate or sufficient to reach policy objectives (Coombs 1980; e.g. McBarnet and Whelan 1991).
} 
Mitchell 1996). ${ }^{3}$ Some of these behaviors can be "automatic", the product of habits and routines. By contrast, "planned" compliance or noncompliance may epitomize the intentional pursuit of various goals, such as to maximize one's utility, fulfill a moral obligation such as duty or trust, or dispose of one's fear of sanctions. They may also sometimes be explained as the result of regulatees' incapacity, incompetence, ignorance or misunderstanding of regulatory prescriptions (e.g. Brehm and Hamilton 1996).

Compliance theorists usually focus on compliance as "planned" rather than "automatic" behavior. In agreement with the Weberian approach to explaining behavior, they consider goal-oriented action as a satisfactory approximation for actual action processes. This has led to many insightful analyses. Yet, to this day fundamental problems remain unsolved, that have hampered the continuous development of compliance theory. Two of them call for attention.

Firstly, compliance theory should account for the empirically demonstrated tendency of regulatees to pursue simultaneously several, heterogeneous goals. Empirical studies show that there can be a combination of material, emotional and normative goals at play in compliance and noncompliance behaviors (int. al. Alm et al. 1995; Fisman and Miguel 2007; Gezelius 2002; Haines and Gurney 2003; Hutter 2001; May 2005; Parker 1999, 2006; Simpson 2002; Tyler 2006; Wenzel 2004, 2005). For instance, a given regulatee may be trying to make a profit, protect oneself against a potential loss, have fun, and act appropriately, all at once. These goals do not easily translate into a common measure of

\footnotetext{
${ }^{3}$ Compliance and non-compliance issues are characterized by "equifinality", namely the existence of several alternative causal explanations for the same effect, and "multifinality", namely the fact that several different effects are consistent with a common cause (George and Bennett 2005: 10).
} 
utility. Hence, compliance theories relying on only one kind of these motives, especially rational actor models of compliance (starting with Becker 1968) ignore and fail to explain a significant share of the empirical reality, as numerous empirical studies have shown (int.al. Braithwaite and Makkai 1991; Grasmick and Green 1980; Paternoster et al. 1983; Paternoster and Simpson 1996).

Various ideas have been put forward to address this problem, but most of them are unsatisfactory. The most common response by compliance theorists has been to combine several models of action. Taken individually, each of these models ignores the complexity of motives observable in realistic settings. Yet, taken together, these models can account for most observations, given that the population of compliers and non-compliers can be divided into, for instance, utilitarian "amoral calculators" (Kagan and Scholz 1984), "bad apples" (Bardach and Kagan 2002) or "opportunists" (Hood 1986) on the one hand, and dutiful "virtuous" actors, "citizens", or "good apples" on the other hand. The best known example is the work of Ayres and Braithwaite (1992). It combines two incompatible theories: rational choice theory (game theory) and the idea that norm internalization in trust relations may overcome opportunistic temptations not to comply. This compromise between "a logic of consequences" and "a logic of appropriateness" (Mitchell 2007) is representative of many contributions to the regulation literature (int. al. Gunningham and Grabosky 1998; Gunningham et al. 2005; Hood 1986; Kagan and Scholz 1984; Mitchell 2007; Scholz 1984; Sherman 1993; van Snellenberg and van de Peppel 2002).

In spite of their unquestionable qualities, these writings are internally inconsistent as a result of their combining incompatible models of goal-oriented action. Only very few integrative and yet consistent frameworks have been proposed so far, including motivational posturing theory (Braithwaite et al. 2007) and Scholz's translation of non- 
material motivations into "heuristics" (Scholz 2003; Scholz and Pinney 1995). None of them, however, has explicitly addressed the effects resulting from interactions between heterogeneous motivations.

In fact, the second problem compliance theorists should resolve is to provide an account for the fact that the various, heterogeneous motivations for compliance or noncompliance are not simply cumulative. They cannot be conceptualized as adding or subtracting to one another, for they interact in various and sometimes counterintuitive ways, leading to empirical effects too significant to be ignored. The best known and best documented example of such interactions is how self-interest can "crowd out" normative or "intrinsic" goals such as altruism, duty, or trust (e.g. Bowles 2008; Frey 1997; McGraw and Scholz 1991: 475-77; Parker 2006: 611-2). But there are other types of interaction as well. For example, it has also been found that emotions interact with a calculative logic in counterintuitive ways, leading to various behavioral patterns incompatible with what a rational model of compliance would predict (Makkai and Braithwaite 1994b).

Only rarely have compliance theorists proposed conceptualizations for these interactions. Many frameworks do not even acknowledge that such interactions exist. Others account for the combined influence of different motives merely in a cumulative way, as for example when social norms are considered a parameter to add or subtract to the regulatee's measure of utility (e.g. Sutinen and Kuperan 1999). Motivation crowding theory (Frey 1997) is a rare exception. It conceptualizes the interaction between material and normative goals as the crowding out of intrinsic motivation by extrinsic motivation. Although a powerful tool, it has been rarely taken up in the regulation literature (Feld and Frey 2007; Le Grand 2003). 
I would argue that failure to address successfully these two issues - accounting for the plurality and heterogeneity of motivations for (non)compliance and for the interactions between these goals - has limited the development of compliance theory on one aspect in particular: the dynamics of compliance behaviors. Solving these issues is key to explaining behavioral changes in responses to regulation, inasmuch as the latter imply "overcom[ing] the existing set of motivations" of regulatees (Gray and Scholz 1993: 199) and fostering a more favorable set of motivations.

In the following, I intend to demonstrate that a goal framing approach of compliance can solve these two issues and thus help explaining the dynamics of compliance and noncompliance.

\section{First step: a taxonomy of goals}

Any approach of compliance behaviors that intends to take up the plurality and variety of goals (what actors intend to achieve) requires a taxonomy of goals. The latter are not all equivalent nor interchangeable: to follow a norm (such as one's duty to obey the law) is not the same thing as to follow one's emotions (such as the desire for revenge), or one's interests (such as securing income or making a profit). To keep this taxonomic exercise at a manageable level of complexity, Lindenberg uses three broad categories: the hedonic goal, the gain goal, and the normative goal. Practically, any more specific goal pursued in a particular situation may be linked with one of them and hence be understood as a particular form of either the hedonic goal, the gain goal, and the normative goal. Each of these three goals points at distinct triggers of individual action that co-exist and mingle in everyday life and in responses to public regulation. 
The hedonic goal bears on the motivation to achieve pleasure and/or stimulation in the accomplishment of a task. It is linked with positive emotions such as happiness, fun, comfort, and their negative counterparts, for example guilt, anger, shame, or discomfort. The hedonic goal is present in almost everything that people do. A propensity to shorttermism often reveals that its influence on choices is predominant, as for instance when anger blinds one to the consequences of one's actions. The relevance of the hedonic goal to the study of regulatory compliance is immediate, for regulatory policies may call and depend on emotions in various ways. For instance, regulation sometimes imposes uncompensated costs on regulatees that may trigger intense emotions. It might be because regulation demands that regulatees perform a behavior they find unpleasant: for example, car drivers should wear seat belts; or, more generally, it might be because compliance implies subjection of various forms and degrees. Also, enforcement may be felt as unjust, disrespectful, or scornful. To be threatened by sanctions may trigger a feeling of fear, and to experience punishment may generate shame, guilt, or anger (Sherman 1993). Regulation and responses to it have also been linked to positive emotions triggered by playful situations or pleasant messages (e.g. Singhal and Greiner 2008), or the "thrill" of breaking the law (Simpson 2002).

The second category of goals is gain. It bears on the motivation to preserve or increase one's resources. An actor acting in a gain frame will be principally attentive to the prospect of a reward or profit (in money, power, influence, free time, etc.). The gain goal is relevant to regulatory compliance in a number of ways. Regulation can contribute to create, sustain, or threaten vested interests that might then play a determinant role in one's response to it: regulation may directly or indirectly yield resources for the benefit of target populations, especially in the very frequent occurrence when rewards (tax reliefs, bonuses, etc.) are 
linked to performing the expected behavior, as in the situation of farmers in Europe or in the US receiving subsidies for their production of crops, milk, or meat. Gain goals are also important when regulators use financial disincentives (such as a tax) or costly sanctions (such as fines or imprisonment), or when they close opportunities for yielding resources. Gain is more generally the central motive attributed to regulatees in the rational-choice deterrence approach to regulatory compliance, and there is ample ground to assume that its more strategic forms can help account for numerous cases of regulatory avoidance, for example in the form of "creative compliance" (Shah 1996).

The normative goal can be summarized as "to act appropriately" or "to do the right thing”. It evokes the normative conformity of classical sociology and the logic of appropriateness of March and Olsen (1989). This refers to the motive to abide by social norms, i.e. rules shared within a group and controlled and sanctioned by its members. The normative goal is tied with identity and the way individuals "self-categorize" (Wenzel 2007). It is also often linked to long-term issues. In fact a propensity not to take advantage of short-term opportunities, as in business relationships (e.g. Lindenberg 2000b) generally reveals the strength of normative goals such as "to honor trust". Multiple social norms can influence responses to regulatory policy. Some of them could be called compliance-prone, evoking one's "feeling of duty" to comply with legal rules (e.g. May 2004). However, not all norms necessarily favor compliance (e.g. Gezelius 2002; Lessig 1995). For instance, group norms may motivate so-called "honor killings" in spite of laws and other social norms unequivocally proscribing them.

Hence, there is not a straightforward link between "morality" or "norms" on the one hand, and compliance on the other. Neither should it be taken for granted that a "strategic" (gain) or "emotional" (hedonic) attitude will necessarily be correlated to "defiance" and 
non-compliance. Rather, all three types of goals may be at play in both noncompliant and compliant behaviors.

As it should be obvious from this brief presentation, the hedonic, gain and normative goals embody well-known "logics of action", that have all been mentioned at various moments in compliance research (most systematically in Suchman 1997). The value added of GFT is to show how these goals interact with each other to determine preferences.

\section{Second step: a model of preference formation}

Actors may pursue multifarious goals, but their choices may not proceed from any sophisticated aggregation or compromise between all the goals in their goal set. The limits of their cognitive capacities make a comprehensive calculus unlikely. In particular, actors cannot attend to all the goals at once. GFT claims that competition between different goals is solved by incomplete attention. More precisely, selective attention implies that there is a foreground to which actors are attentive in priority and a background to which they are only secondarily attentive. This has been commonly referred to as "tunnel vision" (e.g. McCaffery and Baron 2006: 107). Accordingly, elements of one's goal set are distributed between foreground and background. The most influential goal is the one standing in the foreground of one's attention: the goal-frame. The other, weaker goals are in the background.

In the foreground, the goal-frame structures the definition of the situation and works as a filter, selecting knowledge chunks, references and beliefs as well as criteria to sort options (the courses of action available for achieving goals). As such it has a crucial influence on the formation of preferences: alternatives are primarily sorted with respect to their capacity to satisfy the goal-frame. For example, if one is principally pursuing profit-making, the 
most profitable option will be placed at the top of one's preferences, then followed by the other options sorted in function of their decreasing profitability. The framing effect of the dominant goal is thus to focus one's attention on certain dimensions of the option set (profitability) and away from other aspects (political correctness, comfort), possibly to the point where not all options and aspects of options available will actually be known and/or considered by actors. ${ }^{4}$ For instance, it is an empirically well established fact that normoriented actors tend to discount the benefits and costs of options: they are in a normative goal-frame and it makes them inattentive to gain aspects (e.g. Wenzel 2004). Conversely, the enduring practices of banks with regard to salaries and bonuses during the current financial crisis and despite widespread moral condemnation illustrate how being in a gain frame tends to make one inattentive to the appropriateness of one's preferred course of action.

Background goals have an effect on preferences as well. That hinges on the agreement between the preference structure that the foreground goal imposes on the option set and the preference structure that the background goals impose on the option set. If the background goals are compatible with the goal-frame (i.e. their respective preference structures are in agreement), then the preference structure determined by the goal-frame is reinforced, and the probability of choosing the top alternative is close to 1 . For instance, it has been shown that normative behavior is reinforced by (hedonic) feelings of guilt and shame in case of non-conformity by self, or feelings of anger in case of non-conformity by others (e.g. Elster

\footnotetext{
${ }^{4}$ Since selective attention can make actors oblivious of options available to them and of regulation's expectations with regard to what option they should choose, goal framing can also explain certain cases of noncompliance resulting from ignorance or misunderstanding of regulation.
} 
1998; Hopfensitz and Reuben, 2009; Makkai and Braithwaite 1994b). Here, background hedonic goals reinforce the normative foreground goal and make the choice of the most appropriate alternative very likely.

However, if the background goals are incompatible with the goal-frame (i.e. their respective preference structures are in disagreement), then the preference structure determined by the goal-frame is weakened, and the probability of choosing the top alternative is lowered, while that of choosing a second best alternative is raised. More schematically, let us imagine a case of two incompatible goals G1 and G2, G1 being the dominant goal (the goal-frame), and G2 a background goal. Options A, B, C, D, E, are sorted in function of their capacity to satisfy G1, as for instance in:

$$
\mathrm{P}(\mathrm{G} 1) \rightarrow \mathrm{A}>\mathrm{B}>\mathrm{C}>\mathrm{D}>\mathrm{E}
$$

where A brings more satisfaction of goal G1 than B, and then C, and then D, and finally E. G2 being incompatible with G1, the order of preferences for G2 alone is logically the reverse of what it is for G1 (Lindenberg 2001a: 321-3):

$$
\mathrm{P}(\mathrm{G} 2) \rightarrow \mathrm{E}>\mathrm{D}>\mathrm{C}>\mathrm{B}>\mathrm{A}
$$

The joint influence of G1 and G2 implies that, although in the background, the goal G2 may alter the option set determined by the goal-frame G1. The preference structure resulting from the joint influence of these goals could then be such as:

$$
\mathrm{P}(\mathrm{G} 1 / \mathrm{G} 2) \rightarrow \mathrm{B}>\mathrm{A}>\mathrm{C}>\mathrm{D}>\mathrm{E}^{5}
$$

\footnotetext{
${ }^{5}$ To make things clearer here, goals are assumed to be either perfectly compatible or incompatible. However, in reality, even background goals compatible with the frame will create adjustments in the preference structure.
} 
With the distinction between foreground and background goals, one can explain second best choices as the result of the combined influence of different goals.

Different combinations of foreground and background goals can help make sense of a great variety of "logics of action", for example various forms of opportunism. Background normative concerns for actors in a gain goal-frame may lead them to prefer a second-best alternative compatible with their individual or collective long-term interests rather than choose what their immediate self-interest commands. This is what Chaserant calls "enlightened self-interest" (Chaserant 2003). Similarly, the most short-term, "myopic" opportunism may be viewed as a gain goal-frame supported by hedonic background goals, the latter pushing towards choosing the most immediate means to fulfil one's ends, sometimes at the expense of one's long-term interests.

The degree of agreement or disagreement between background goals and the preference structure imposed by the foreground goal is called "salience" (Steglich 2003: 20). In the case where goal-frame and background goals are only weakly incompatible, the salience of the goal-frame is strong, and the alternative that brings the most satisfaction to the goalframe will be almost certainly chosen. But the more the goal-frame and the background goals are incompatible, the lower the salience, and therefore the less discrimination between the alternatives, so that it becomes less certain which of them will be chosen (Lindenberg 2001a: 323)

Very low salience generates randomness in preferences and behaviors. This is arguably an unstable and short-lived situation, therefore a too weak foreground goal will tend to be replaced by one of the background goals. The new goal-frame will have been the strongest incompatible background goal (Lindenberg 1993: 22). The other background goals, those compatible with the frame, will be weak themselves, otherwise the salience of the former 
goal-frame would not have become so low (Steglich 2003: 21). This substitution of one goal by another as goal-frame is called dynamic frame displacement.

Dynamic frame displacement is the main process for explaining changes in dominant goals: substitution of a goal by another in the foreground of an actor's attention may lead to completely different choices. GFT allows us hence to integrate in a theoretically consistent fashion different logics of action, but also to interpret the interplay between them leading to specific choices and eventually changes in behaviors. Dynamic frame displacement is at the centre of various changes in patterns of regulated behavior that I will discuss in the next section.

\section{Third step: mechanisms}

The encompassing categories "hedonic", "gain" and "normative" goals and the model of preference formation outlined earlier provide the means to understand how actors may form preferences on the basis of several and heterogeneous goals, and how these preferences may change as a result of interactions between these goals. However, to account for the fact that "regulation is an important way of ordering priorities" so that regulatees behave in a certain way (Hutter 2001: 295), there must be an account of how public regulators can influence this process of preference formation. In this section, I argue that this process can be fruitfully conceptualized as affecting two main variables: the regulatee's goals (what the regulatee wants to achieve), and the regulatee's options (the courses of action available for achieving goals). Regulatory policy's impact on these two variables can be analyzed with two independent mechanisms. Firstly, regulatory policy varies the goal set (i.e. the frame's salience) through what I call "goal signals"; and secondly, it varies the option set by modifying the relative consequences of options (figure 1). 
Figure 1 about here

For each of these two mechanisms several examples will follow from a brief general presentation. In accordance with this paper's focus, most of them bear on regulatory policy, with an emphasis on the law, rewards, sanctions, and information tools.

\section{First mechanism: goal signaling}

In a striking experiment, Liberman, Samuels and Ross (2004) have showed that depending on the way a social dilemma game was labelled, the goals of participants to that game changed dramatically. Calling the game "Wall Street game" led to only $31 \%$ of cooperative behaviours, while calling it "community game" led to $66 \%$ of cooperative behaviours. In another experiment, Keizer, Lindenberg and Steg (2008) have showed that depending on the absence or presence of visible signs of noncompliance in a given situation - e.g. a wall covered with graffiti despite a very visible "no graffiti" sign - individuals tended to abide more or less to social norms, such as the rule that one should not litter. In the orderly situation (no graffiti), 33\% littered compared with $68 \%$ in the disorderly situation (wall covered with graffiti).

In this section I claim that a more general mechanism of "goal signalling" can be deduced from such examples and many others. In the same fashion as naming the game influenced the relative force of opportunistic (gain) and collaborative (normative) goals, multiple elements in one's environment can channel one's attention towards particular goals and away from others. They can be of all sorts: events, behaviors or messages. Inasmuch as one of these elements evokes a particular goal - like the game's name in the 
previous example - it signals that goal, thus introducing it (if it was not there already) or reinforcing it in the receiver's goal set. As a result, goal signals can either strengthen or weaken one's goal-frame. ${ }^{6}$

In the regulation literature, goal signals appear multifarious, but they are principally of two kinds. Fellow regulatees appear to be an important source of influence affecting one's goals. For example, Roch, Scholz and McGraw found that interactions with peers in a network contributed to the strength of one's feeling of "moral obligation" and "guilt" with regard to tax compliance/avoidance (Roch et al. 2000: 788; see also Toby 1957; Gezelius 2002; Williams and Hawkins 1986: 554). Regulation appears as another paramount source of goal signals. This is acknowledged in various strands of literature, where institutionalized rules and policy tools are shown to influence the very goals of target populations (int. al. Bowles 2008; Jones and Cullis 2003; Le Grand 2003; Streeck 2009; Scholz and Gray 1990; Sunstein 1996).

Goal signaling should not be confused with other uses of the concept of "signaling" that can also be found in the regulation literature, and which refer essentially to information addressed to regulatees regarding the consequences of their options: for instance, the hazards of smoking (Licari 2003). Indeed, goal signaling does not relate to the information actors hold about their options, which they use to compare one to another. More fundamentally, it refers to their goals, and how these can be altered "in a relatively automatized, non-deliberative" manner by capturing their attention (Shah and Kruglanski 2002: 380). Hence, goal signaling and its "goal pull” effect refers to a process logically anterior to the assessment by actors of their options. Therefore, the distinction between goal

\footnotetext{
${ }^{6}$ For other experimental evidence of this "goal pull” effect, see Shah and Kruglanski (2002).
} 
signaling and relative consequences is one between the automatic and the deliberative aspects of preference formation. Yet, a particular piece of regulation will likely have both dimensions, altering both one's goal set and relative consequences at the same time.

Since goal signals reinforce goals, they affect the salience of goal-frames. Goal signals compatible with one's goal-frame will likely sustain or reinforce its salience. Goal signals incompatible with one's goal-frame will likely weaken its salience. ${ }^{7}$ For instance, regulatees in a normative goal-frame may receive incompatible gain signals, but not compatible normative signals. As a result, the salience of their normative goal-frame may decrease. Repeated incompatible goal signals may ultimately trigger a frame displacement. The outcome of the competition between incompatible goals for one's attention is ultimately an empirical issue.

As I shall now illustrate, goal signals are pervasive in various contributions to the literature on regulation and can help make sense of many of its results.

\section{Hedonic signals}

Studies of regulatory enforcement and its role in compliance and noncompliance abound with examples of emotional responses, especially anger, fear, guilt and/or shame (int.al. Braithwaite 1989; Fineman and Sturdy 1999; Gezelius 2002: 312; Goldsmith 2005;

\footnotetext{
${ }^{7}$ Goal signals will likely be more effective if they are: personalized i.e. they target regulatees personally rather than as members of generic groups; incarnate (sent by another, identifiable individual, and particularly one that matters for the receiver, i.e. an important other: peer, sibling, authority figure, etc.); and repeated.
} 
Grabosky 1995: 350; Makkai and Braithwaite 1994b; Parker 2006; Scholz and Pinney 1995: 494; Sherman et al. 1992). All strongly suggest that emotions have an important role to play in various types of responses to regulation, and that regulatory practices themselves contribute in various ways to reinforcing hedonic goals.

Hedonic signals may be seen in various forms, including harsh enforcement. Makkai and Braithwaite have found that for already "highly emotional" regulatees, deterrent threats triggered anger, which appeared to motivate subsequent noncompliance (Makkai and Braithwaite 1994b: 361-3). Hedonic signals may also be found in encouragements or similar reactions from peers (e.g. Williams and Hawkins 1986: 554), eventually leading to revengeful actions against regulators or third parties (Sherman 1993: 465-66).

Studies on the role of fear (e.g. Scholz and Pinney 1995) can be rephrased as evidence of strong hedonic signals sent with threats of sanctions, that either put actors in a hedonic goal-frame where disposing of one's fear is the main motivation for compliance, or strengthen fear avoidance in the background of one's gain or normative goal-frame. ${ }^{8}$ Guilt and shame are also hedonic aspects frequently discussed in the literature. Goal signals reinforcing guilt and shame avoidance in one's goal set can have a durable and positive influence on compliance because these hedonic goals positively interact with normative supports for compliance, such as one's duty to obey the law (Braithwaite 1989; Hopfensitz and Reuben 2009; Makkai and Braithwaite 1994a; Parker 2006; Sherman 1993; Sherman et al. 1992; Tyler 2006).

\footnotetext{
${ }^{8}$ Chikudate (2009) provides a striking example where fear of sanction literally drives one's attention away from elementary safety considerations, with catastrophic consequences.
} 
Policy tools may also trigger more positive hedonic goals. For example, Sunstein and Thaler tell of a campaign launched in Texas to tackle roadside littering. It used posters, video clips or t-shirts tying the expected behavior with the stereotypes of a "tough guy" and "proud to be Texan", with which the target population (men between the age of 18 and 24) used to identify itself (Thaler and Sunstein, 2009: 64-5). By adjusting to appealing symbols and figures (many celebrities took part to the ads), the "Don't mess with Texas" campaign pulled hedonic goals as well as normative goals. It is credited with very significantly reducing roadside litter in Texas. Another source of hedonic signals is unexpected rewards, most likely verbal or symbolic ones, which have also been said to strengthen motivations for compliance (Frey 1997: 18; Singhal and Greiner 2008:48; Sunstein, 1996: 2031).

\section{Gain signals}

Gain signals abound in the most common tools of regulation: as stickers in public transports informing travelers of penalty fares, as pamphlets and videos warning individuals of the legal and personal costs of sexual harassment at work, as road signs recalling drivers of the likely consequences of noncompliant driving, etc.

Gain signals play an especially important role in advanced capitalist societies, where they contribute to installing and sustaining gain goal-frames for the performance of multifarious tasks. Streeck argues that capitalist institutions "assume, and thereby encourage, a utility-maximizing disposition on the part of actors" (Streeck 2009: 28). There is also a growing literature that demonstrates experimentally how various forms of regulation and especially the use of monetary incentives and disincentives push actors to act in a gain goal-frame. They do so by consistently channeling attention towards the costs and benefits of alternative courses of action (e.g. Ariely 2009; Bowles 2008; Frey 1997). Shifts 
from a "moral" or "normative" logic of action to a "self-interested" or "utilitarian" logic as a result of such regulatory changes have been discussed in the regulation literature before (de Bruijn and Hufen 1998: 18; McGraw and Scholz 1991: 475-7).

The negative impact of gain signals on normative goal-frames is a matter of salience. Gain signals may topple a normative goal-frame if the latter's salience is low. That generally happens if it is not strengthened by compatible background goals and frequent normative signals (see below). Various pieces of research suggest that normative goalframes are often easily and rapidly displaced by gain signals, while the reverse - displacing a gain goal-frame with normative signals - seems more difficult to achieve and usually takes time (Frey 1997; Lindenberg 2000a; Streeck and Thelen 2005: 33).

\section{Normative signals}

Normative signals can be discovered in multiple instances of regulatory policy. Laws themselves tautologically bring regulatees' attention to their duty to obey the law, and hence can contribute to strengthen normative goals (Sunstein 1996: 2032; e.g. Licari 2003: 289). Pictures or objects, such as a uniform, may contribute to strengthening normative goals as well. Information tools are also sending normative signals when they point at a norm upheld in the target group, as the "Don't mess with Texas" campaign discussed above, or campaigns of birth control tying having children to patriotism (Weiss and Tschirhart 1994: 89). Tax can also be a normative signal, as in the case of the so-called "sin taxes" imposed on alcohol or tobacco (Bressers and O'Toole 2005: 143). This can have dramatic effects on target populations when the "relative appropriateness"9 of alternative

\footnotetext{
${ }^{9}$ The relative consequences of options that matter for the pursuit of a normative goal (see below).
} 
courses of action is simultaneously changed. For example, Rosenthal tells of a tax on plastic bags introduced in Ireland in 2002 that led to $94 \%$ reduction in plastic bag use. As she writes, "plastic bags were not outlawed, but carrying them became socially unacceptable" (Rosenthal 2008). In other words, the tax had triggered a normative goalframe and made it inappropriate to use plastic bags.

It is fair to say that the success of these strategies tying behavioral expectations to social norms depends in large part on "dormant normative obligations" (Lindenberg 1983: 465), namely dispositions learned in the regulatees past, and which may then endure in their goal set as foreground or background goals. This has important implications for explaining the dynamics of so-called "voluntary" compliance, and calls for more scholarly attention to be given to facts, behaviors and regulations sending goal signals compatible or incompatible with compliance-prone normative goals.

Sanctions are an important vector for normative signals. Sociologists have long noticed that sanctions are inseparable from norms, so that whenever sanctions disappear normative behaviors tend do so as well. Without the idea of goal signaling, this is puzzling, given that actors in a normative goal-frame tend to be inattentive to the costs induced by sanctions (e.g. Wenzel 2004). Sanctions matter for the salience of normative frames not because of the costs they impose on noncompliers, but because they signal to all what is appropriate behavior and what is not.

Taking count of the normative signals of sanctions enables and makes sense of the important claim that social norms and deterrence are not independent factors of compliance (Sherman et al. 1992; Williams and Hawkins 1986). "Voluntary" compliance is indeed often correlated to strict controlling and sanctioning practices towards regulatees who do not comply (Lederman 2003; Scholz 1984). This is because these punishments send 
normative signals and henceforth strengthen normative goals in the goal sets of targeted regulatees, whether the latter are in a normative goal-frame, in that case punishments work as "a reminder of preexisting commitments to comply" (Thornton et al. 2005: 266, 280-1), or in a gain goal-frame, in that case they "boost deterrence effects" (Wenzel 2004: 547).

By way of consequence, if sanctions disappear, the related normative goal is not regularly strengthened by compatible signals any more. Competition from rival goals may then alter substantially the shape of the goal set, and sometimes trigger a frame displacement. There is then a possibility that violations of related norms will multiply (e.g. Coleman 1990: 485-6; Gezelius 2002: 312).

Dramatic changes in goal sets could thus take place when taxes and financial disincentives replace sanctions. The normative signals sent by sanctions may disappear when harmful practices become "priced", for instance through a system of payments due in relation to the damage caused, without any reference to (il)legality (e.g. Braithwaite 1981/1982; Ogus 1998; a similar argument has been brought forth regarding the application of civil sanctions instead of criminal ones to punish crime; for a review of the literature see Simpson 2002: 70-1).

Also, anything that could be seen as evidence that threats of sanctions are not deterring non-compliers sends hedonic (feeling cheated) and gain signals (wasting resources) that are incompatible with the feeling of duty to comply. For instance, compliers may hear about or witness widespread and/or unpunished non-compliance (Grabosky 1995: 349; Vandenbergh 2003: 115; e.g. Aitken 2001: 190; Keizer et al. 2008; Tittle and Rowe 1973). As a result, the norm may lose its moral force and opportunistic responses to rules may multiply. 
As I have shown in this sub-section, regulators may influence one's goals in various ways, and this influence can be conceptualized and studied as attempts to capture and orient one's attention with "goal signals". As I shall now explore in more detail, regulators may also alter the relative consequences of alternative courses of action, and thus change the second ingredient of preference formation: options.

\section{Second mechanism: relative consequences}

The idea of relative consequences as a determinant of preferences is widespread in economics and also in regulation studies under the heading of "relative prices". Ogus (1998: 770) states thus that "an important function of the law is to attach prices to choices". However, relative prices are only a part of the consequences actors may anticipate when sorting between options. It refers only to costs and benefits, which matter in a gain goalframe but not in other goal-frames. Therefore, a richer and more diverse approach to goals such as that of GFT requires that other kinds of consequences be taken into account as well: those that matter in a hedonic frame, which I call "relative pleasure / stimulation", and those that matter in a normative frame, which I call "relative appropriateness".

In the process of preference formation the distinction between the goal-frame and the background goals is all-important, and one should differentiate between the impact of a change in relative consequences directly taken up by the goal-frame and that of a change taken up only by the background goals (Lindenberg 1992; Lindenberg and Frey 1993).

If relative consequences change in aspects directly taken up by the goal-frame - for instance, prices change and the goal-frame is gain -, then their effect on preference formation and eventually behavior will likely be important, and in fact all the more so if the goal-frame's salience is high. However, if relative consequences change in aspects taken up 
only by background goals - for example, prices change and the goal-frame is normative -, their effect will likely be weak or nil. In other words, the net effect of changes in relative consequences is dependent on the nature of these consequences and on the shape of the goal set, especially the salience of the goal-frame.

Perhaps the simplest way to illustrate this interaction between relative consequences and goals is to borrow from a well established and often replicated result of the compliance literature. In a number of empirical studies, scholars consistently observed a measurable effect of legal sanctions (fines, imprisonment, etc.) on the behaviors of actors declaring no commitment to social norms, i.e. actors who were not in a normative goal-frame (see literature review in Vandenbergh 2003; also Bowles 2008; Simpson 2002).

For example, Wenzel showed that perceived legal sanctions were strongly correlated to compliance when regulatees did not declare strong personal norms. The correlation was even stronger if they perceived that peers could also impose informal sanctions. Since these regulatees were not in a normative goal-frame but more likely in a gain goal-frame, they were directly attentive to relative prices and thus to the costs induced by formal and informal sanctions. Hence, backing up legal sanctions by informal ones heightened the attractiveness of compliance compared to other options (Wenzel 2004: 563). As a consequence, increasing the severity of sanctions for actors in a gain goal-frame would likely yield a rapid and significant response (increasing compliance rates), as demonstrated experimentally by Steglich (2003).

By contrast, actors in a normative goal-frame are indifferent to prices and attentive to appropriateness. In Wenzel's study (2004: 559-60), there appeared to be no correlation between the severity of sanctions and the level of compliance for those regulatees who declared strong personal compliance norms or a high level of identification to the group 
upholding the compliance norm. For these actors, who were in a normative goal-frame, sanctions mattered only for the normative signals they carried. Their impact in terms of relative prices was marginal.

Therefore, changing the severity of sanctions would not have a significant impact on their preferences nor on their behaviors. Only significant changes sending incompatible gain signals - especially a steep reduction in penalties or a rise in contrary incentives would reinforce enough the background gain goal so that it displaces the normative goalframe. Then the relative prices effect would operate in full. Again, Steglich (2003) provides supporting evidence.

Combining relative consequences and goal signaling enables us to take up a variety of regulatory strategies and a number of responses to these strategies by targeted regulatees. The following sections provide several examples, each focusing on a particular type of relative consequences, beginning with the best known relative prices.

\section{Relative prices}

Changing relative prices constitutes undoubtedly the best known and probably the most frequently mentioned way to change regulatees' preferences and improve compliance. Relative prices prove to be a major cause of responses to regulation in a number of situations and especially in those where the law and the authority of regulators are not supported by norms of legitimacy and by enforcement, and hence where normative goals are therefore absent or weak. It appeared to be the case with compliance with international law regulating intentional pollution at sea (Mitchell 1994). Before oil prices rose, policies to control deliberate discharges from oil tankers had generally failed, principally because 
such behavior was particularly difficult to monitor. However, the 1973 and 1978 oil price shocks made cleaning tanks at sea more expensive since an increasingly valuable part of the freight was lost in the process. This change in relative prices resulted in a significant decrease in oil pollution at sea (Mitchell 1994: 227), a case of "co-incidental compliance" (ibid.: 256). Thus, regulatory strategies relying on relative prices may either fail or rather succeed as a result of uncontrolled changes in prices, such as those that follow from an economic boom or a depression (Mitchell 2007: 909).

Another example where changing relative prices had strong effects as a result of an already well-established gain goal-frame is the desegregation policy in the American south. In the early 1960s, it appears that a majority of white southern businessmen were favorable to desegregation as it would allow them to hire blacks (that would help push wages down) or have them as clients (Lessig 1995: 966 n57). However, southern businessmen also faced the risks of informal sanctions applicable in case they did not respect the segregation norm, such as boycott. The Civil Rights Act of 1964 changed that. It signaled every Southerner's duty to abide by American law and also claimed that segregation was inappropriate. As a result, violations of the segregation norm became much less likely to be enforced, which meant a change in relative prices for businesses. Besides, violating the Act exposed all to sanctions, especially the owners of the businesses where segregation was applied. As a result, the Act could yield its strongest effects among businessmen (Lessig 1995: 965-67; also Horne 2004: 1056).

An evolution in relative prices will have the greatest impact on preferences when combined with signals pulling the gain goal. Tax policy in Russia in the 1990s is a telling tale of these joint mechanisms. In 1994, the Russian federal government started handling its suppliers a claim on the government in lieu of payment, for instance in the form of a 
treasury obligation. This claim could be used to pay tax arrears. It had its upside for the government, as these tax offsets could bring (non-cash) revenue immediately and in an easier and less politically costly manner than through tax enforcement. As a result of this and of similar schemes being introduced year after year, suppliers to the government started accumulating tax arrears. The schemes were a transaction between the government and companies and as such they were unequivocal gain signals. They also enabled companies to obtain payment for their supplies to the government (which was paying above-market prices), and thus altered also the relative prices of trading with the government rather than with other buyers. In addition to the example set by government suppliers failing on their tax obligations, more gain signals were sent when these tax offset schemes were extended to all businesses, thus generalizing a transactional approach to tax compliance. As a result an increasing number of companies accumulated tax arrears and started to trade claims on the budget between themselves. As Aitken explains, "in some schemes the claims were securitized, and an active and highly lucrative secondary market quickly developed" (Aitken 2001: 188). The commissions received in these exchanges were another change in relative prices. Also, businesses made an increasing profit out of non-compliance, and that probably contributed to an increasingly opportunistic response to tax law from previously compliant companies. It is likely that failure to enforce compliance in high profile cases (notably Gazprom) also contributed to further weaken compliance-prone goals. Tax collection itself grew difficult as companies intentionally starved themselves of cash. Overall tax returns fell very significantly in 1994 , the decrease in cash compliance worsening in 1995 and 1996. The relative prices effect had worked well, and in fact so well that the federal government had found itself stuck in a "low revenue trap". 
As this sub-section has shown, a goal framing approach to compliance can take up relative price effects. However, in comparison to other models, a goal framing approach expands greatly the range of relative consequences considered by addressing the influence of relative pleasure/stimulation and the relative appropriateness of options.

\section{Relative pleasure/stimulation}

Public regulators sometimes directly and intentionally change the relative pleasure or stimulation derived from different courses of action. A famous example is a policy to tackle non-compliance with traffic regulation in Bogota (Colombia), a city then famous for its very high prevalence of noncompliant behaviors. In March 1995, pantomime artists were hired by the City council to replace the traffic police at the city's crossroads (Caballero 2004; Singhal and Greiner 2008). Their task was to publicly mock non-compliers, either by following pedestrians crossing the road elsewhere than at the crosswalk, or by expressing displeasure at drivers stopping on the crosswalk and thus obstructing the way for pedestrians. Mocking made noncompliance a more unpleasant course of action, at the same time as it created "a teaching-learning moment in that very instant for the offender and the on-lookers" (Singhal and Greiner 2008: 47). It also certainly sent normative signals to reinforce normative dispositions, i.e. "making visible the (in)appropriate behavior of citizens in a playful manner" (ibid.)

This took place in par with intense and often amusing communication by the then mayor Antanas Mockus addressing the problem of lawlessness in Bogota, sending additional normative and hedonic signals to the public. This combination of compatible hedonic and normative signals and changes in the relative pleasure/stimulation derived from alternative courses of action brought significant improvements in driver and pedestrian behavior as 
well as less traffic accidents (ibid. p. 49). Thus, putting regulatees in the right goal set with goal signals and adjusting options on the corresponding dimension proved efficient. This strategy has limits of course. For example, there is little doubt that pedestrians or drivers whose attention was focused on an urgent trip would not have cared to be ridiculed, since another goal was temporarily channeling their attention: an important meeting or a medical emergency.

The relative pleasure or stimulation derived from alternative options can also be at stake in responses to regulation in ways that regulators themselves do not control or may not be able to predict. This is sometimes an unintended consequence of technological progress. Thus, "disruptive innovations" (Bower and Christensen 1995) may make certain regulated tasks less unpleasant: the internet has made numerous administrative procedures less burdensome, magnetic transport cards have made public transport easier, etc.

But regulatory policy may also constrain actors in an activity that gives them a certain pleasure or stimulation, or it may ask them to perform an activity that yields a form of displeasure. The case of seat-belts is well known. Peltzman argued that when seat-belts were introduced, they constrained drivers and hence reduced the hedonic returns of driving (a feeling of freedom, power, autonomy, etc.) Therefore, in order to achieve the same level of stimulation than before, drivers tended to drive more recklessly, thus offsetting for a while the safety gains of seat-belts (Peltzman 1975). This offsetting effect, if genuine, was short-lived. Addressing Peltzman's study, further research found that drivers wearing seatbelts did not drive less carefully, and sometimes drove more carefully, while risk-taking drivers were actually less likely to buckle up (Friedland et al. 1990: 191-2). Seat-belts and information tools linked to them probably have had their own signaling effect, successfully focusing an increasing number of drivers' attention on safety as a relevant goal. 
Conversely, it can be argued that those who persist in not buckling up probably do so because they are in a hedonic goal-frame, as suggested by them being frequently of young age, and more amenable to drive fast, or to drink and drive (ibid.)

A study by Bamberg and Schmidt (1999) provides another compelling example of the role played by the relative pleasure / stimulation derived from alternative courses of action. In a small German university town, a preferential fare for bus use was introduced, and a new peripheral bus line installed. This obviously changed the relative travel times and costs of the alternative modes of transport available: the bus, the car, and the bike. It had some success, but several students who used to go to the university by car and had switched to the bus after the reform later came back to using their car. This is puzzling from a perspective that focuses on material aspects alone, because the second behavioral change was not linked to a change in relative prices: in the meantime, they had not changed. It is less puzzling from a GFT perspective.

These students used to travel by car, which may be costly, but also rewarding in terms of comfort, autonomy, and stimulation. Indeed, driving is linked to strong hedonic goals, but the reforms had sent gain signals (a cheap travel solution called "Semester ticket"), thus successfully displacing the hedonic goal-frame of drivers with a gain goal-frame. They had also adjusted relative prices so that taking the bus had reached high in many students' order of preferences (Bamberg and Schmidt 1999: 494, table IV). Yet, it appears that the hedonic goal remained strong in the background, keeping the salience of the new gain goal-frame low and thus weakening the overall effect of the new relative prices. Then, the gain goalframe grew weaker, possibly as a result of incompatible hedonic signals sent by unpleasant and very common experiences linked to taking the bus, such as: having to stay standing as all seating is taken, waiting for the bus in the cold, having to suffer a not-too-likeable co- 
traveler, or a clumsy or unsympathetic driver, etc. These surely contributed to reinforcing the hedonic goal in the background, until it retook its place as the goal-frame. Hence, the relative pleasure/stimulation of options came to dominate again the process of preference formation, and therefore the car became again the preferred alternative.

\section{Relative appropriateness}

People in a normative goal-frame are attentive to the relative appropriateness of options, and they tend to sort their option set accordingly. Regulators often try to change relative appropriateness with information campaigns. This has limits as other goals may well lead regulatees to choose second-best responses rather than those expected from them by regulators (e.g. Weiss and Tschirhart 1994: 88). Changing relative appropriateness may also prove difficult to achieve when important others (siblings, authority figures, etc.) repeatedly and consistently conform with the targeted norm and make repeated statements that confirm the appropriateness of that course of action, as it is the case in religious or traditional communities. The enduring practices of female genital mutilation or so-called "honor crimes" within certain communities in occidental countries is a telling tale of how hard it can be to change relative appropriateness. Therefore it has been argued that authority figures should contribute to redefining the limits of what is appropriate and what is not, otherwise information campaigns are likely to fail or even backfire (Sunstein 1996: 2049).

A strategy used to change relative appropriateness is what Lessig called "ambiguation" (Lessig 1995). Ambiguation refers to strategies creating normative ambiguity by way of information campaigns and legislation. The relative appropriateness of a given course of action deemed appropriate according to a given norm is being changed by challenging it as a violation of another existing and shared but otherwise yet unrelated norm. As a result the 
appropriateness of the targeted option is brought into question, and in fact lowered. At the same time, sanctioning the targeted behavior becomes also more appropriate.

A very contemporary example of successful ambiguation is the intensive and diversified communication campaign focusing on the Muslim headscarf in France from the early 2000s, as well as the law of March 2004 banning Muslim headscarves in public schools, and the current debate over forbidding face-covering veils in all public places. The strategy undertaken by successive governments in these years consisted in challenging the headscarf as a violation of the norm of secularity, formulated in a law from 1905 separating the Church from the State and therefore applicable to the symbols, buildings, representatives and employees of the State. Information tools and ultimately the law itself presented headscarves worn by pupils as an attack against secularity and the Republic. Critics who emphasized that headscarves were not inappropriate inasmuch as wearing them was protected by the freedom to practice one's religion inscribed in French law and by the norm of religious tolerance failed to counteract the change in the relative appropriateness engineered by regulators, so-called "intellectuals" and journalists (Bowen 2008; Scott 2007). As a consequence, there have been increasing reports of Muslim women who, although they were neither students nor public employees, have increasingly suffered from illegal discrimination, often from the part of public agents, because they were wearing a headscarf: in bank branches, on the streets, during civil wedding ceremonies, or when driving (AFP 2010; Bowen 2008; Khorsokhavar 2009). This transformation in relative appropriateness has created a puzzling situation where discriminatory acts against women wearing headscarves have been at the same time compliant with expectations publicly expressed by politicians in the government or the parliament and yet also noncompliant 
with those formulated in law, at least until the latter will have been rewritten to accommodate them.

To sum up, an extended view of relative consequences going beyond relative prices to include consequences important in normative and hedonic goal-frames, combined to the mechanism of goal signaling, provide a powerful toolkit for the explanation of observed responses to regulatory policies. Both mechanisms are logically complementary, often working simultaneously, and yet clearly analytically distinct.

\section{Conclusion}

The framework outlined in this paper focuses on how public regulation influences regulatees' motives (goal set) and alternatives (option set), thus influencing the way their preferences become structured. Its two essential mechanisms, goal signaling and relative consequences, combine automatic and deliberative processes to account for the impact of regulatory policy on preferences. As the multifarious quotes from the literature demonstrate, a goal framing approach to compliance can take up a great variety of empirical findings from various streams of research on regulatory compliance. This result is achieved without any loss of theoretical consistency, thanks to Lindenberg's goal framing theory, which can take up the simultaneous influence of several heterogeneous motives on individual decisions. The theoretical framework also provides an account of the behavioral changes resulting from interactions between these goals. Therefore, the two problems identified in the current state of the literature have been solved, and this is a better model for compliance analysis than previous ones. 
Conceptualizing compliance as the result of a competition between rival goals implies that behavioral change results from a threshold effect (also Jacob 1980). That threshold depends on a regulatee's goal set (goal-frame and background goals) and option set (alternatives available), and it is ultimately an empirical issue. This indeterminacy in the framework is by and large intentional, so as to be able to account for the various and sometimes contradictory effects that a single measure may have for different regulatees (Grabosky 1995). ${ }^{10}$

At this stage a goal framing theory of regulatory compliance remains principally an interpretative tool for making sense of observed data. However, studies that intend to generate hypotheses and predictions will also find a goal framing approach of use, given that they include a preliminary phase of detailed data collection designed to identify the main characteristics of the situations where compliant and noncompliant behaviors take place. Besides, previous work on measuring motivations in real and experimental settings has paved the way for the operationalization of a goal framing approach of compliance (Crissy and Le Grand 2004; Tenbrunsel and Messick 1999).

The great potential of such a richer view of compliance is for stakeholders and especially regulators in the public and private domains. Examples abound of failures where the blame is put on the goals of actors not being what they should be. For instance, the pioneer of microcredit Muhammad Yunus recently blamed the excessive opportunism of lenders for the shortcomings of microcredit. He declared: "Microcredit should be seen as an opportunity to help people get out of poverty in a business way, but not as an opportunity to

\footnotetext{
${ }^{10}$ For example, a goal framing approach to compliance can reconcile together a number of divergent empirical results bearing on the effects of legal and informal sanctions (Sherman et al. 1992; Simpson 2002; Williams and Hawkins 1986).
} 
make money out of poor people" (MacFarquhar 2010). This and other examples suggest that a more complex view of goals combined to theoretical tools explaining how the latter may be changed could help improve regulatory effectiveness. The often highly simplistic assumptions made by policymakers with regard to what motivates regulatees prove Bueno de Mesquita right when he claims that "decision making is the last frontier in which science has been locked out of government and business" (Bueno de Mesquita 2009: xxi). It is time for regulators to adopt thicker views of what motivates regulatees and to build robust strategies acknowledging the complementarities of different goals and the combined effects of goal signals and relative consequences on regulatees' preferences (see also Le Grand 2003; Lindenberg and Steg 2007).

\section{References}

AFP. 2010. Amende pour une femme portent le niqab au volant de sa voiture. 23 April.

Aitken, Brian. 2001. Falling Tax Compliance and the Rise of the Virtual Budget in Russia. IMF Staff Papers 48:180-208.

Alm, James, Isabel Sanchez, and Ana De Juan. 1995. Economic and Noneconomic Factors in Tax Compliance. Kyklos 48 (1):3-18.

Ariely, Dan. 2009. Predictably Irrational. New York: HarperCollins.

Ayres, Ian, and John Braithwaite. 1992. Responsive Regulation. New York and Oxford: Oxford University Press.

Bamberg, Sebastian, and Peter Schmidt. 1999. Regulating Transport: Behavioural Changes in the Field. Journal of Consumer Policy 22:479-509.

Bardach, Eugene, and Robert A. Kagan. 2002. Going by the Book. The Problem of Regulatory Unreasonableness. Second edition ed. New Brunswick \& London: Transaction Publishers. Becker, Gary S. 1968. Crime and Punishment: An Economic Approach. Journal of Political Economy 76 (March-April):169-217.

Bowen, John. 2008. Why did the French rally to a law against scarves in schools? Droit et société (68):33-52. 
Bower, Joseph L., and Clayton M. Christensen. 1995. Disruptive Technologies: Catching the Wave. Harvard Business Review (January-February).

Bowles, Samuel. 2008. Policies Designed for Self-Interested Citizens May Undermine "The Moral Sentiments": Evidence from Economic Experiments. Science 320:1605-9.

Braithwaite, John, and Toni Makkai. 1991. Testing an Expected Utility Model of Corporate Deterrence. Law \& Society Review 25 (1):7-40.

Braithwaite, John. 1981/1982. The Limits of Economism in Controlling Harmful Corporate Conduct. Law and Society Review 16 (3):481-504.

Braithwaite, John. 1989. Crime, shame and reintegration. Cambridge: Cambridge University Press. Braithwaite, John. 2002. Rewards and Regulation. Journal of Law and Society 29 (1):12-26.

Braithwaite, Valerie, Kristina Murphy, and Monika Reinhart. 2007. Taxation Threat, Motivational Postures, and Responsive Regulation. Law \& Policy 29 (1):137-158.

Brehm, John, and James T. Hamilton. 1996. Noncompliance in Environmental Reporting: Are Violators Ignorant, or Evasive, of the Law? American Journal of Political Science 40 (2):444-477. Bressers, Hans, and Laurence J. O'Toole. 2005. Instrument Selection and Implementation in a Networked Context. In Designing Government. From Instruments to Governance, edited by P. Eliadis, M. M. Hill and M. Howlett. Montreal \& Kingston: McGill-Queen's University Press. Bueno de Mesquita, Bruce. 2009. Predictioneer. London: The Bodley Head.

Caballero, Maria Cristina. 2004. Academic turns city into a social experiment. Harvard University Gazette, 11 March.

Chaserant, Camille. 2003. Cooperation, Contracts and Social Networks: From a Bounded to a Procedural Rationality Approach. Journal of Management and Governance 7:163-186.

Chikudate, Nobuyuki. 2009. If human errors are assumed as crimes in a safety culture: A lifeworld analysis of a rail crash. Human Relations 62 (9):1267-1287.

Coleman, James S. 1990. Foundations of Social Theory. Cambridge, MA: Harvard University Press.

Coombs, Fred S. 1980. The bases of noncompliance with a policy. Policy Studies Journal 8 (6): 885-92.

Crilly, Tessa, and Julian Le Grand. 2004. The motivation and behaviour of hospital Trusts. Social Science \& Medicine 58:1809-1823.

de Bruijn, Hans A., and Hans A.M. Hufen. 1998. The traditional approach to policy instruments. In Public Policy Instruments. Evaluating the Tools of Public Administration, edited by B. G. Peters and F. K. M. van Nispen. Cheltenham: Edward Elgar. 
Elster, Jon. 1998. Emotions and Economic Theory. Journal of Economic Literature XXXVI (1):4774.

Feld, Lars P., and Bruno S. Frey. 2007. Tax Compliance as the Result of a Psychological Tax Contract: The Role of Incentives and Responsive Regulation. Law \& Policy 29 (1):102-120. Fineman, Stephen, and Andrew Sturdy. 1999. The Emotions of Control: A Qualitative Exploration of Environmental Regulation. Human Relations 52 (5):631-663.

Fisman, Ray, and Edward Miguel. 2007. Corruption, Norms and Legal Enforcement: Evidence from Diplomatic Parking Tickets. Journal of Political Economy 115 (6):1020-1048.

Frey, Bruno S. 1997. Not Just for the Money: An Economic Theory of Personal Motivation. Cheltenham: Edward Elgar.

Friedland, Martin, Michael Trebilcock, and Kent Roach. 1990. Regulating Traffic Safety. In Securing Compliance: Seven Case Studies, edited by M. Friedland. Toronto: University of Toronto Press.

George, Alexander L., and Andrew Bennett. 2005. Case Studies and Theory Development in the Social Sciences. Cambridge, Mass.: MIT Press.

Gezelius, Stig S. 2002. Do Norms Count? State Regulation and Compliance in a Norwegian Fishing Community. Acta Sociologica 45 (4):305-314.

Goldsmith, Andrew. 2005. Police reform and the problem of trust. Theoretical Criminology 9 (4):443-470.

Grabosky, Peter. 1995. Counterproductive Regulation. International Journal of the Sociology of Law 23:347-369.

Grasmick, Harold G., and Donald E. Green. 1980. Legal Punishment, Social Disapproval and Internalization as Inhibitors of Illegal Behavior. The Journal of Criminal Law and Criminology 71 (3):325-335.

Gray, Wayne B., and John T. Scholz. 1993. Does Regulatory Enforcement Work? A Panel Analysis of OSHA Enforcement. Law \& Society Review 27 (1):177-213.

Gunningham, Neil, and Peter Grabosky. 1998. Smart Regulation. Designing Environmental Policy. Oxford: Oxford University Press.

Gunningham, Neil, Dorothy Thornton, and Robert A. Kagan. 2005. Motivating Management: Corporate Compliance in Environmental Protection. Law \& Policy 27 (2):289-316.

Haines, Fiona, and David Gurney. 2003. The Shadows of the Law: Contemporary Approaches to Regulation and the Problem of Regulatory Conflict. Law \& Policy 25 (4):353-380.

Hood, Christopher. 1986. The tools of government. Chatham: Chatham House. 
Hopfensitz, Astrid, and Ernesto Reuben. 2009. The Importance of Emotions for the Effectiveness of Social Punishment. The Economic Journal 119 (540):1534-1559.

Hopkins, Andrew. 1994. Compliance with What? The Fundamental Regulatory Question. Brit. J. Criminol. 34 (4):431-443.

Horne, Christine. 2004. Collective Benefits, Exchange Interests, and Norm Enforcement. Social Forces 82 (3):1037-1062.

Hutter, Bridget. 1997. Compliance: Regulation and Environment. Oxford: Oxford University Press. Hutter, Bridget. 2001. Regulation and Risk: occupational health and safety on the railways. Oxford: Clarendon Press.

Jacob, Herbert. 1980. Deterrent Effects of Formal and Informal Sanctions. Law \& Policy Quarterly $2(1): 61-80$.

Jones, Philip, and John Cullis. 2003. Key Parameters in Policy Design: The Case of Intrinsic Motivation. Journal of Social Policy 32 (4):527-547.

Kagan, Robert A., and John T. Scholz. 1984. The Criminology of the Corporation and Regulatory Enforcement Strategies. In Enforcing Regulation, edited by K. Hawkins and J. Thomas. Hingham, Mass.: Kluwer-Nijhoff.

Keizer, Kees, Siegwart Lindenberg, and Linda Steg. 2008. The Spreading of Disorder. Sciencexpress 322 (5908):1681-1685.

Khosrokhavar, Farhad. 2009. Ce que la loi sur la burqa nous voile. Le Monde, 31 July.

Kruglanski, Arie W., James Y. Shah, Ayelet Fishbach, Ron Friedman, Woo Young Chun, and David Sleeth-Keppler. 2002. A Theory of Goal Systems. In Advances in Experimental Social Psychology, Vol. 34, edited by M. P. Zanna. San Diego: Academic Press.

Le Grand, Julian. 2003. Motivation, Agency and Public Policy: Of Knights and Knaves, Pawns and Queens. Oxford: Oxford University Press.

Lederman, Leandra. 2003. The Interplay Between Norms and Enforcement in Tax Compliance. Ohio State Law Journal 64 (6):1453-1514.

Lessig, Lawrence. 1995. The Regulation of Social Meaning. The University of Chicago Law Review $62(3): 943-1045$.

Licari, Michael J. 2003. Bureaucratic Discretion and Regulatory Success without Enforcement. In Politics, Policy, and Organizations. Frontiers in the Scientific Study of Bureaucracy, edited by G.

A. Krause and K. J. Meier. Ann Arbor: The University of Michigan Press.

Lindenberg, Siegwart, and Bruno S. Frey. 1993. Alternatives, Frames, and Relative Prices: A

Broader View of Rational Choice Theory. Acta Sociologica 36:191-205. 
Lindenberg, Siegwart, and Linda Steg. 2007. Normative, Gain and Hedonic Goal Frames Guiding Environmental Behavior. Journal of Social Issues 63 (1):117-137.

Lindenberg, Siegwart. 1983. Utility and Morality. Kyklos 36 (3):450-468.

Lindenberg, Siegwart. 1989. Social Production Functions, Deficits, and Social Revolutions. Rationality and Society 1 (1):51-77.

Lindenberg, Siegwart. 1992. An Extended Theory of Institutions and Contractual Discipline. Journal of Institutional and Theoretical Economics 148 (1):125-154.

Lindenberg, Siegwart. 1993. Framing, Empirical Evidence, and Applications. In Jahrbuch für Neue Politische Ökonomie. Tübingen: Mohr (Siebeck).

Lindenberg, Siegwart. 1998. Solidarity: Its Microfoundations and Macrodependence. A Framing Approach. In The Problem of Solidarity. Theories and Models, edited by P. Doreian and T. Fararo. Amsterdam: Gordon and Breach.

Lindenberg, Siegwart. 2000a. The extension of rationality: Framing versus cognitive rationality. In L'Acteur et ses raisons, edited by J. Baechler and F. Chazel. Paris: PUF.

Lindenberg, Siegwart. 2000b. It Takes Both Trust and Lack of Mistrust: The Workings of Cooperation and Relational Signaling in Contractual Relationships. Journal of Management and Governance 4:11-33.

Lindenberg, Siegwart. 2001a. Intrinsic Motivation in a New Light. Kyklos 54 (2-3):317-342.

Lindenberg, Siegwart. 2001b. Social Rationality as a Unified Model of Man (Including Bounded Rationality). Journal of Management and Governance (5):239-251.

MacDonald, Paul K. 2003. Useful Fiction or Miracle Maker: The Competing Epistemological Foundations of Rational Choice Theory. American Political Science Review 97 (4):551-565.

MacFarquhar, Neil. 2010. Banks Making Big Profits From Tiny Loans. The New York Times, 13 April.

Makkai, Toni, and John Braithwaite. 1994a. Reintegrative Shaming and Compliance with Regulatory Standards. Criminology 32:361-385.

Makkai, Toni, and John Braithwaite. 1994b. The Dialectics of Corporate Deterrence. Journal of Research in Crime and Delequency 31 (4):347-373.

March, James G., and Johan P. Olsen. 1989. Rediscovering Institutions: The Organizational Basis of Politics. New York: Free Press.

May, Peter J. 2004. Compliance Motivations: Affirmative and Negative Bases. Law \& Society Review 38 (1):41-68.

May, Peter J. 2005b. Compliance Motivations: Perspectives of Farmers, Homebuilders, and Marine Facilities. Law \& Policy 27 (2):317-347. 
May, Peter J., and Robert S. Wood. 2003. At the Regulatory Front Lines: Inspectors' Enforcement Styles and Regulatory Compliance. Journal of Public Administration Research and Theory 13 (2):117-139.

McBarnet, Doreen and Christopher Whelan. 1991. The elusive spirit of the law: formalism and the struggle for legal control. Modern Law Review 54 (6): 848-73.

McCaffery, Edward J., and Jonathan Baron. 2006. Thinking about Tax. Psychology, Public Policy, and Law 12 (1):106-135.

McGraw, Kathleen M., and John T. Scholz. 1991. Appeals to Civic Virtue Versus Attention to SelfInterest: Effects on Tax Compliance. Law \& Society Review 25 (3):471-498.

Mitchell, Ronald B. 1994. Intentional Oil Pollution at Sea. Cambridge: The MIT Press.

Mitchell, Ronald B. 1996. Compliance Theory: An Overview. In Improving Compliance with International Environmental Law, edited by J. Cameron, J. Werksman and P. Roderick. London: Earthscan.

Mitchell, Ronald B. 2007. Compliance Theory: Compliance, Effectiveness, and Behaviour Change in International Environmental Law. In Oxford Handbook of International Environmental Law, edited by J. Brunee, D. Bodansky and E. Hey. Oxford: Oxford University Press.

Ogus, Anthony. 1998. Taxes and Financial Impositions as Regulatory Instruments. The Modern Law Review 61 (6):767-788.

Parker, Christine. 1999. How to Win Hearts and Minds: Corporate Compliance Policies for Sexual Harassment. Law \& Policy 21 (1):21-48.

Parker, Christine. 2006. The "Compliance" Trap: The Moral Message in Responsive Regulatory Enforcement. Law \& Society Review 40 (3):591-622.

Paternoster, Raymond, and Sally Simpson. 1996. Sanction Threats and Appeals to Morality: Testing a Rational Choice Model of Corporate Crime. Law \& Society Review 30 (3):549-583.

Paternoster, Raymond, Linda E. Saltzman, Gordon P. Waldo, and Theodore G. Chiricos. 1983.

Perceived Risk and Social Control: Do Sanctions Really Deter? Law \& Society Review 17 (3):457480.

Peltzman, Sam. 1975. The Effects of Automobile Safety Regulation. Journal of Political Economy 83 (4):677-725.

Roch, Christine H., John T. Scholz, and Kathleen M. McGraw. 2000. Social Networks and Citizen Response to Legal Change. American Journal of Political Science 44 (4):777-791.

Rosenthal, Elisabeth. 2008. Motivated by a Tax, Irish Spurn Plastic Bags. The New York Times, 2 February. 
Scholz, John T. 1984. Cooperation, Deterrence, and the Ecology of Regulatory Enforcement. Law \& Society Review 18 (2):179-224.

Scholz, John T. 2003. Contractual Compliance and The Federal Income Tax System. Journal of Law \& Policy 13:139-203.

Scholz, John T., and Neil Pinney. 1995. Duty, Fear, and Tax Compliance: The Heuristic Basis of Citizenship Behavior. American Journal of Political Science 39 (2):490-512.

Scholz, John T., and Wayne B. Gray. 1990. OSHA Enforcement and Workplace Injuries: A Behavioral Approach to Risk Assessment. Journal of Risk and Uncertainty 3:283-305. Scott, Joan Wallach. 2007. The Politics of the Veil. Princeton: Princeton University Press. Shah, Atul K. 1996. Creative compliance in financial reporting. Accounting, Organizations and Society 21 (1):23-39.

Shah, James Y., and Arie W. Kruglanski. 2002. Priming against your will: How accessible alternatives affect goal pursuit. Journal of Experimental Social Psychology 38:368-383.

Sherman, Lawrence W. 1993. Defiance, Deterrence, and Irrelevance: A Theory of the Criminal Sanction. Journal of Research in Crime and Delequency 30 (4):445-473.

Sherman, Lawrence W., Douglas A. Smith, Janell D. Schmidt, and Dennis P. Rogan. 1992. Crime, Punishment, and Stake in Conformity: Legal and Informal Control of Domestic Violence. American Sociological Review 57 (October):680-690.

Sills, Ben, Natalie Weeks. 2010. Greek Tax-Dodgers Threaten Papandreou's Plan to Cut Budget Gap. Bloomberg News, 15 February, http://www.bloomberg.com/apps/news?pid=20601109\&sid=apSz28ifLL9U.

Simpson, Sally S. 2002. Corporate Crime, Law, and Social Control. Cambridge: Cambridge University Press.

Singhal, Arvind and Karen Greiner. 2008. Performance Activism and Civic Engagement Through Symbolic and Playful Actions. Journal of Development Communication 19:43-53.

Steglich, C. 2003. The framing of decision situations. Automatic goal selection and rational goal pursuit, Department of Behavioral and Social Sciences, ICS Disseration Series, University of Groningen, NL, Groningen.

Streeck, Wolfgang, and Kathleen Thelen. 2005. Introduction: Institutional Change in Advanced Political Economies. In Beyond Continuity: Institutional Change in Advanced Political Economies, edited by W. Streeck and K. Thelen. Oxford: Oxford University Press.

Streeck, Wolfgang. 2009. Institutions in History. Bringing Capitalism Back In. MPIfG Discussion Paper (09/8). 
Suchman, Mark C. 1997. On beyond interest: rational, normative and cognitive perspectives in the social scientific study of law. Wisconsin Law Review 1997 (3):475-501.

Sunstein, Cass R. 1996. On the expressive function of the law. University of Pennsylvania Law Review 144 (2021-2053).

Sutinen, Jon G., and K. Kuperan. 1999. A socio-economic theory of regulatory compliance. International Journal of Social Economics 26 (1/2/3):174-193.

Tenbrunsel, Ann E., and David M. Messick. 1999. Sanctioning Systems, Decision Frames, and Cooperation. Administrative Science Quarterly 44 (4):684-707.

Thaler, Richard H., and Cass R. Sunstein. 2009. Nudge. London: Penguin.

Thornton, Dorothy, Neil Gunningham, and Robert A. Kagan. 2005. General Deterrence and Corporate Environmental Behavior. Law \& Policy 27 (2):262-288.

Tittle, Charles R., and Alan R. Rowe. 1973. Moral appeal, sanction threat, and deviance: An experimental test. Social Problems 20 (4):488-498.

Toby, Jackson. 1957. Social Disorganization and Stake in Conformity: Complementary Factors in the Predatory Behavior of Hoodlums. The Journal of Criminal Law, Criminology, and Police Science 48 (1):12-17.

Tyler, Tom R. 2006. Psychological Perspectives on Legitimacy and Legitimation. Annual Review of Psychology 57:375-400.

van Snellenberg, Ton, and Rob van de Peppel. 2002. Perspectives on Compliance: Non-Compliance with Environmental Licences in the Netherlands. European Environment 12:131-148.

Vandenbergh, Michael P. 2003. Beyond Elegance: A Testable Typology of Social Norms in Corporate Environmental Compliance. Stanford Environmental Law Journal 22:55-144.

Weiss, Janet A., and Tschirhart. 1994. Public Information Campaigns as Policy Instruments. Journal of Policy Analysis and Management 13 (1):82-119.

Wenzel, Michael. 2004. The Social Side of Sanctions: Personal and Social Norms as Moderators of Deterrence. Law and Human Behavior 28 (5):547-567.

Wenzel, Michael. 2005. Motivation or rationalisation? Causal relations between ethics, norms and tax compliance. Journal of Economic Psychology 26:491-508.

Wenzel, Michael. 2007. The Multiplicity of Taxpayer Identities and Their Implications for Tax Ethics. Law \& Policy 29 (1):31-50.

Williams, Kirk R., and Richard Hawkins. 1986. Perceptual Research on General Deterrence: A Critical Review. Law \& Society Review 20 (4):545-572. 


\section{FIGURES}

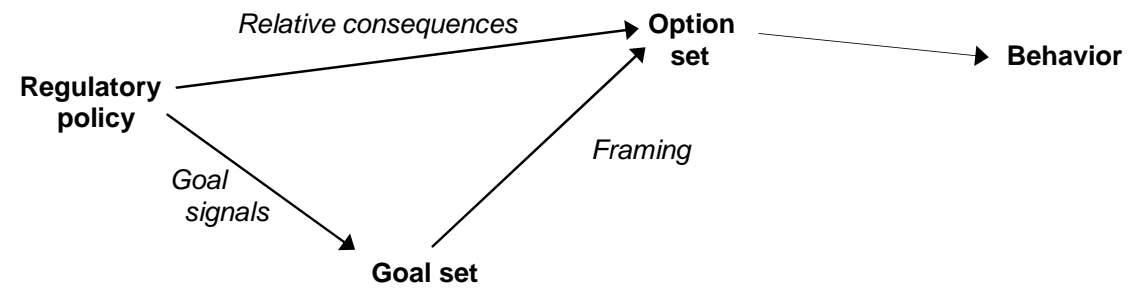

Figure 1: Overview of the theoretical framework 